\title{
Diagnóstico microbiológico de infecciones de transmisión Sexual. Parte II. ITS virales
}

\author{
M. José Martínez G.
}

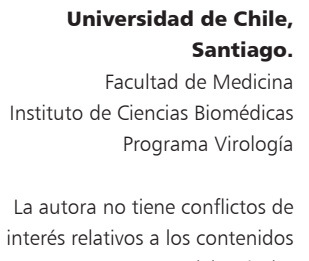

del artículo.

Recibido: 25 junio 2009 Aceptado: 27 agosto 2009

Correspondencia a: M. José Martínez Galofre mmartine@med.uchile.cl

\section{Microbiologic diagnosis of sexually transmitted diseases: Part II. STD of viral origin}

Sexually transmitted diseases are highly prevalent and a public health concern worldwide. Herpes simplex virus (HSV) and human papilloma virus (HPV) are described. The development of rapid, sensible and specific diagnostic assays has been difficult because of their pathogenic features. In the last years, molecular biology based techniques allowed a better and wider range of diagnosis, as in the HPV-cancer association. In this article, standardized diagnostic methodologies for HSV and HPV are reviewed.

Key words: Herpes simplex virus, human papilloma virus, STI, diagnosis.

Palabras clave: Virus herpes simplex, virus papiloma humano, infecciones de transmisión sexual, diagnóstico.

$\mathrm{L}$ as infecciones de transmisión sexual (ITS) son un problema de la salud pública mundial, siendo consideradas hiper-endémicas en muchos países subdesarrollados ${ }^{1}$. Millones de personas se infectan y reinfectan cada año, constituyéndose en el grupo de enfermedades infecciosas notificables más común en la gran mayoría de los países, particularmente en el grupo de 15 a 50 años y en la infancia ${ }^{1}$. Su control es fundamental dado el alto número de casos agudos, complicaciones y secuelas, su impacto socioeconómico y por favorecer el contagio del virus de inmunodeficiencia humana $(\mathrm{VIH})^{2}$.

Dado el aumento en las conductas sexuales de riesgo, la menor edad de inicio de la actividad sexual, el mayor número de parejas sexuales en la vida de las personas, entre otros factores, es recomendable contar con métodos de diagnóstico precisos y rápidos, que posibiliten un tratamiento precoz. De esta manera se podría disminuir el número de pacientes que son fuente de contagio durante el período de espera de los resultados ${ }^{2}$.

Las ITS comprenden aquellas que se adquieren por contacto con lesiones clínicas o subclínicas en piel y mucosas, como también las que son transmitidas en la secreción vaginal y el semen. Entre las primeras clasificamos a aquellos virus que replican en el tejido cutáneo y mucoso, como son: los virus herpes simplex tipo 1 (VHS1) y tipo 2 (VHS-2), los virus papiloma humanos (VPH) y los virus del molusco contagioso (VMC). Dentro del grupo de virus transmitido por las secreciones genitales, asociados a leucocitos, encontramos a: VIH, virus de hepatitis B, Human T cell lymphotropic virus 1 (HTLV-1), virus de Epstein Barr y citomegalovirus. Estos últimos no serán tratados en este artículo.

\section{Virus herpes simplex}

Los virus herpes simplex pertenecen a la familia $\mathrm{Her}$ pesviridae, son virus $\mathrm{ADN}$, icosaédricos y envueltos, de aproximadamente $150 \mathrm{~nm}$ de diámetro. Al igual que los demás miembros de esta familia, tienen la capacidad de persistir de manera latente y de reactivarse. Serológicamente se diferencian en dos tipos, los cuales comparten cerca de $50 \%$ de homología genética.

Si bien, ambos pueden infectar la mucosa genital, el VHS-2 es el principal agente de úlcera genital en el mundo. Generalmente, se considera una infección de diagnóstico clínico; sin embargo, en ocasiones se requiere de la certificación del laboratorio, especialmente en pacientes inmunodeficientes, mujeres embarazadas y recién nacidos.

Prueba de Tzanck. Una de las técnicas más antiguas y simples de realizar es la prueba de Tzanck, en la cual se tiñe un frotis de la lesión ulcerada, con solución Giemsa y se observa a microscopia de luz buscando queratinocitos multinucleados. Su sensibilidad global para casos de VHS es de $63 \%$, pudiendo alcanzar a $85 \%$ en muestras recientes de pústulas. Tiene el inconveniente de no distinguir entre serotipos de VHS ni diferenciarlo del virus varicela-zoster ${ }^{3}$. Considerando que es un examen simple, barato, rápido y que no requiere gran implementación, es recomendable en las etapas iniciales de las lesiones vesiculo pustulosas; su rendimiento decae considerablemente con el paso de los días ${ }^{3}$.

Aislamiento viral (AV). El AV en cultivo celular es una técnica que entrega la certeza de identificar virus 
replicante en la muestra clínica tomada y, por lo tanto, continúa siendo la técnica de referencia en el diagnóstico de enfermedades muco-cutáneas. Sin embargo, su sensibilidad es inferior a la reacción de polimerasa en cadena (RPC) ya que la frecuencia de detección de este virus en piel o mucosas es cuatro veces mayor mediante esta última técnica ${ }^{4}$. El AV tiene además la desventaja de ser un procedimiento lento, que requiere una infraestructura de laboratorio compleja y costosa, personal entrenado, y es muy susceptible a los procedimientos de toma, transporte y almacenamiento de las muestras clínicas, ya que requiere indemnidad y una mayor cantidad de partículas virales $^{5}$. Generalmente, el efecto citopático se presenta a las 48 horas pero puede tardar hasta cinco días. Este es confirmado posteriormente mediante la detección de antígenos virales por medio de anticuerpos monoclonales, utilizando inmunofluorescencia ${ }^{5,6}$. Se agrega a lo anterior, datos que demuestran que el rendimiento de esta técnica decae con el aumento de la temperatura ambiental, comprobándose que en período estival es cinco veces menor que en invierno ${ }^{4}$. Su sensibilidad puede alcanzar al $80,9 \%$ con una especificidad de $100 \%$, comparándolo con la RPC 5 .

Detección de antígenos. Las técnicas de detección de antígenos virales, como son la inmunofluorescencia directa realizada en frotis de lesiones o la detección mediante ELISA (EIA), muestran valores inferiores al AV, comparándolos igualmente con RPC. La sensibilidad descrita para la EIA es de $\sim 65,2 \%$ y su especificidad de $98,7 \%$. Estos valores son superiores si la comparación se realiza con el AV (62 a 100\% y 95,2 a 100\%, respectivamente). Estos métodos tienen la ventaja de ser rápidos y fáciles de realizar, pero podrían detectar partículas virales no infecciosas ${ }^{5}$.

En nuestro país son escasos los laboratorios que cuentan con estas técnicas, por lo que especialmente el aislamiento viral se utiliza mayoritariamente con fines de investigación.

Técnicas de biología molecular. En otras muestras como LCR, biopsias, humor vítreo y sangre, la RPC es la técnica de elección, dado el bajo rendimiento del AV. Esta técnica ha mostrado alcanzar sensibilidad y especificidad cercanas al 100\%, incrementando el diagnóstico en 22 a $27 \%$ frente al AV y también permite tipificar al VHS detectado ${ }^{5,7,8}$. Es rápida, entregando un resultado en aproximadamente $5 \mathrm{~h}$ pero su gran inconveniente es su mayor costo.

Si bien la RPC en tiempo real demuestra una sensibilidad y especificidad similar a la RPC convencional sólo demora alrededor de una hora, gracias a la rapidez de intercambios de temperatura en los ciclos, facilitado por los capilares de vidrio en los cuales se realiza la reacción que son calentados y enfriados por aire ${ }^{7,6}$. El resultado de la amplificación del ADN se observa en la medida que se va produciendo, sin necesidad de realizar una electroferesis posteriormente. Aunque el costo es su gran limitante, es una técnica poco laboriosa, se disminuye la posibilidad de contaminación cruzada y su sensibilidad es muy superior ya que se detectan bajas copias de ADN por reacción, lo que permite identificar cuadros atípicos y recurrencias herpéticas ${ }^{6,8}$. Las técnicas cuantitativas no han demostrado ser necesarias aún para el manejo terapéutico de los pacientes ${ }^{8}$. Sin duda, el principal punto vulnerable a la contaminación intra-laboratorio continua siendo durante la preparación del ADN (técnica de extracción) previo a la RPC. Es necesario observar todas las normas de trabajo e incluir controles negativos que se procesen desde el inicio de éstas. Cada día más centros de diagnóstico nacionales cuentan con esta técnica, con lo que se está logrando un mayor número de casos diagnosticados y tratados oportunamente.

Diagnóstico serológico. El método de identificación serológica de referencia es el western blot, el cual puede diferenciar entre anticuerpos de tipo $\mathrm{IgM}$ e $\mathrm{IgG}$, dirigidos contra antígenos de VHS-1 y de VHS-2. Esta técnica sólo se realiza en algunos centros de investigación del mundo. El tiempo requerido para la formación de IgG es de 21 a 42 días desde la infección inicial, aunque la mayoría tiene anticuerpos detectables entre los 21 y 28 días $^{9}$. Estos anticuerpos posiblemente se prolonguen toda la vida; sin embargo, existen reportes de pacientes en los cuales la IgG específica se hace indetectable con los años ${ }^{10}$. Los anticuerpos tipo IgM se detectan mediante western blot a los 9 a 10 días luego de la exposición y duran 7 a 14 días. En algunos individuos pueden perdurar hasta por 6 semanas. Su sensibilidad alcanza el 79\% y su especificidad al $100 \%{ }^{9}$.

Los métodos rápidos de inmunoensayo de tipo ELISA clásicos presentan reacción cruzada entre los dos tipos virales, por lo que no son útiles en la práctica clínica. Por otra parte la $\operatorname{IgM}$ puede detectarse tardíamente o bien elevarse en las recurrencias herpéticas, situación que complica aún más la interpretación de estos ensayos ${ }^{9,11}$. En los últimos años se han desarrollado y licenciado ensayos que identifican la IgG específica contra la glicoproteína G (gpG) de VHS-2, con buena sensibilidad y especificidad, ya que esta gpG es distinta de la que contiene el manto del VHS-1 ${ }^{10,11}$. Esta técnica permite estudios de seroprevalencia más acuciosos, diagnóstico de infección en pacientes sin sintomatología específica, al igual que la identificación de personas susceptibles. Esta última situación es especialmente importante en mujeres embarazadas, parejas en las cuales sólo uno manifiesta la enfermedad, y en inmunocomprometidos. En los últimos años se han desarrollado técnicas serológicas rápidas 
tendientes a obtener un resultado en pocos minutos y pudiesen ser muy útiles a futuro ${ }^{12}$. Aun así, no se debe perder de vista el hecho que la serología positiva no nos indica el sitio de infección, ni nos entrega un pronóstico del cuadro clínico del paciente. Es así como en los casos de primoinfección genital por HSV-1, en una población con una alta tasa de infección a temprana edad, la identificación de anticuerpos específicos no permite realizar el diagnóstico etiológico de la patología genital. Diferentes estudios han señalado que la sensibilidad y especificidad de estos ensayos están en rangos de 85 a $100 \%$ y 80 a $98 \%$ respectivamente ${ }^{10}$. Los valores predictores positivos y negativos se ven influenciados por la seroprevalencia de la población, siendo mayor el porcentaje de falsos positivos en poblaciones con seroprevalencias bajas $(<5 \%)^{10}$. Esta serología está disponible en nuestro país y distintos estudios han encontrado seroprevalencias para VHS-2 de 14\% en mujeres adultas embarazadas, $43 \%$ en pacientes consultantes a centros de ETS y de $76 \%$ en pacientes infectados por $\mathrm{VIH}^{13-15}$.

\section{Virus papiloma humano}

Los virus papiloma humanos pertenecen a la familia Papillomaviridae. Son virus ADN, doble hebra, de aproximadamente 8.000 pares de bases, icosaédricos, de $55 \mathrm{~nm}$ de diámetro y no tienen envoltura. Posee pocos genes, algunos de los cuales son altamente conservados entre los más de 100 genotipos distintos que hasta ahora se han identificado en el hombre ${ }^{16}$. Estos se clasifican en géneros, siendo los más importantes aquellos que infectan las mucosas y la piel ( $\alpha$-papillomavirus) y los que infectan la piel asociados a la epidermodisplasia verruciforme ( $\beta$-papillomavirus $)^{16}$. La infección genital por VPH constituye una de las ITS de mayor ocurrencia, tanto en nuestro país, como en el mundo entero. Uno de los factores que determina la producción de lesiones malignas, tanto anales como genitales, es el genotipo viral. Es así que el VPH ha sido clasificado en aquellos de bajo riesgo, alto riesgo y un tercer grupo de virus probablemente carcinogénicos ${ }^{17}$. La presencia de VPH en sujetos sanos ha sido identificada como un factor de riesgo para la adquisición del VIH debido a la mayor vascularización de las lesiones causadas por el $\mathrm{VPH}^{18}$. Estos pacientes infectados por VIH llegan a tener múltiples genotipos y además una mayor proporción de genotipos oncogénicos.

Técnicas de biología molecular. El condiloma acuminado o verruga genital es la manifestación clínica más frecuente de la infección por VPH en mucosa. El rol de este virus en la génesis del cáncer cérvico-uterino, como de otras áreas genito-anales, ha impulsado el desarrollo de técnicas diagnósticas capaces de identificar la presencia viral y de genotipificarlo mediante ensayos de biología molecular, ya que este virus no replica en monocapas convencionales de cultivo celular. El mayor problema en el diagnóstico de laboratorio de esta infección es la falta de una técnica referente, reconocida, confiable y utilizada por la mayoría de los investigadores y laboratorios de diagnóstico clínico. Gran parte de las publicaciones están realizadas con técnicas in house, las cuales no pueden ser comparadas posteriormente con otras. De manera similar, las muestras utilizadas al igual que la toma de éstas varían, de acuerdo a la técnica empleada. Para muchas de las RPC que se mencionarán a continuación se puede utilizar cualquier tipo de muestra; citológica, tejido, biopsia incluida en parafina, teniendo cuidado en la forma como se ha mantenido hasta su procesamiento ya que algunas requerirán de métodos de extracción de ADN.

Captura híbrida. Es una técnica que identifica secuencias del ADN viral de un cierto número de genotipos agrupados en alto y bajo riesgo. Si bien está aprobada por FDA y se utiliza en nuestro país, ha demostrado un número importante de falsos negativos frente a otras técnicas más sensibles ${ }^{19}$. El método de captura híbrida 2 (HC2) basado es una técnica de amplificación de señal en fase líquida. $\mathrm{Su}$ sensibilidad es menor que la de la mayoría de las técnicas de amplificación y dado que utiliza una mezcla de sondas no puede ser utilizada para la genotipificación individual ${ }^{20}$. En muestras citológicas y de tejidos es posible identificar secuencias de VPH de alto riesgo utilizando métodos de hibridación de ADN in situ. La sensibilidad varía según el ensayo que se utilice y en su realización no sólo se requiere entrenamiento sino que consumen tiempo, por lo que no son las más apropiadas para utilizar en diagnóstico de laboratorio rutinario ${ }^{20}$.

La RPC que amplifica secuencias consenso del gen que codifica para la proteína viral L1 es la más ampliamente utilizada, encontrándose protocolos que utilizan diferentes estrategias como los partidores degenerados MY09/11, o sobrepuestos como en los sistemas Amplicor, partidores GP5+/6+ que contienen secuencias que permiten uniones erradas en condiciones de baja exigencia de RPC, o los partidores SPF que contienen residuos de inosina en posiciones ambiguas $^{20}$. Algunos ensayos de RPC anidada, en los cuales se amplifica posteriormente secuencias internas, han demostrado una mayor sensibilidad en la detección del amplio número de genotipos virales ${ }^{19}$. Para posteriormente genotipificar estos amplificados se debe recurrir a técnicas de hibridación, secuenciación o restricción enzimática con endonucleasas (RFLP). Todas ellas conllevan un tiempo largo, infraestructura y personal capacitado. Además, la secuenciación y el RFLP son menos sensibles y no permiten diferenciar los genotipos en una infección mixta. Por lo tanto, son poco útiles en diagnóstico clínico. Para los genotipos más prevalentes de VPH también se han 
desarrollado RPC específicas, incluso en tiempo real, con lo cual es posible diagnosticar aquellos de mayor riesgo, por ej.: VPH-16 y VPH-18, y además cuantificarlos. Sin embargo, existe la limitante actual en los equipos de RPC en tiempo real que sólo permiten un número muy reducido de sondas marcadas por lo que no sería posible realizar genotipificaciones a partir de un amplificado consenso ${ }^{20}$.

El problema de las infecciones múltiples es cada vez más importante dada la característica de persistencia de estas infecciones, el alto número de re-infecciones y el aumento de la población inmunocomprometida. Resolver esto requiere de metodologías que permitan simultáneamente la identificación de distintos genotipos. Es así como las RPC realizadas en secuencias consenso, seguidas de hibridaciones reversas han demostrado ser una de las mejores herramientas de diagnóstico de laboratorio para estas infecciones. Estos métodos se basan en la hibridación de amplificados consenso marcados con oligos de VPH tipo específicos inmovilizados en filtros. Actualmente existe el reverse line blot (RLB) que se realiza con posterioridad a la RPC con los partidores MY09/11, o la RPC consenso GP5+/6+, y un line probe assay (LiPa) que utiliza los SPF. Los sistemas de detección de estas hibridaciones pueden ser colorimétricas o quimioluminiscentes. Actualmente existen ensayos que han cambiado el soporte de filtro por vidrio o plástico, resultando en micro arreglos de sondas de VPH tipo específicas, las cuales son igualmente útiles pero de un alto costo y otros métodos cuantitativos basados en tecnología de arreglo en suspensión Luminex. Este último detecta la unión de amplificados consenso GP5+/6+ con sondas de VPH tipo específicas, que están unidas a perlas de poliestireno marcadas con fluoresceí$\mathrm{na}^{20}$. De esta manera, se podría realizar un seguimiento de los pacientes vacunados y de aquellos con estadios iniciales de procesos neoplásicos, con el fin de identificar la persistencia de uno más genotipos, cuantificarlos y demostrar la aparición de nuevos genotipos virales ${ }^{20}$.

En nuestro país se cuenta con laboratorios que realizan diagnóstico de VPH, genotipificando mediante RPC específicas o hibridación reversa.
La demostración de ARNm transcritos de genes que codifican para los genes virales E6 y E7 es utilizada en estudios de investigación de cáncer ya que determina actividad replicativa viral y no sólo presencia del genoma en la muestra estudiada, por lo que su correlación con la potencial transformación celular es mayor. De manera similar, es de interés la demostración de la integración del genoma viral mediante la amplificación de transcritos de oncogenes de papilomavirus (APOT) ${ }^{20}$.

La detección de genotipos asociados a infecciones en piel ha comenzado a concitar el interés de grupos de investigadores, quienes han desarrollado metodologías que identifican estos tipos virales y han demostrado su utilidad en patologías como cáncer de piel no melanoma en pacientes sometidos a trasplantes ${ }^{21}$.

Diagnóstico serológico. Dado que estos virus originan infecciones localizadas en la piel y mucosas, sin un paso sanguíneo importante, la formación de anticuerpos específico no constituye un elemento central de defensa antiviral y su medición por técnicas serológicas se restringe a ensayos de investigación ${ }^{22}$.

\section{Resumen}

Las Infecciones virales de transmisión sexual son altamente prevalentes y constituyen un problema de salud pública en el mundo. Entre los agentes que se contagian por esta vía, se describe acerca de virus herpes simplex (HSV) y virus papiloma humano (HPV). Las características patogénicas de estas infecciones han dificultado la implementación de técnicas diagnósticas rápidas, sensibles y específicas para el diagnóstico clínico habitual. En los últimos años las metodologías diagnósticas sustentadas en la biología molecular han permitido mejorar y ampliar el rango de diagnóstico posible para estos agentes infecciosos y relacionarlos con otras patologías, como es el caso de HPV y cáncer. En el presente artículo se revisan metodologías diagnósticas implementadas para el diagnóstico microbiológico de HSV y de HPV.

\section{Referencias}

1.- De Schryver A, Meheus A. Epidemiology of sexually transmitted diseases: the global picture. Bull World Health Org 1990; 68 (5): 639-54. Review

2.- Gerbase A, Toscano C, Titan S, Cuchí P, González-Salvatierra R, Zacarías F. Sexually transmitted diseases in Latin America and the Caribbean. Pan Am J Public Health 1999; 6 (5): 362-70.

3.- Ozcan A, Senol M, Salgam H, Seyhan M,
Durmaz R, Aktas E, et al. Comparison of the Tzanck test and polymerase chain reaction the diagnosis of cutaneous herpes simplex and varicella zoster virus infection. Int J Dermatol 2007; 46: 1177-9.

4.- Wald A, Huang M, Carrell D, Selke S, Corey L. Polymerase reaction for detection of herpes simplex virus (HSV) DNA on mucosal surfaces: Comparison with HSV isolation in cell culture. J Infect Dis 2003; 188 (1): 1345-51.

5.- Slomka M J, Emery L, Munday P E, Moulsdale M, Brown D G W. A comparison of PCR with virus isolation and direct antigen detection for diagnosis and typing of genital herpes. J Med Virol 1998; 55: 177-83.

6.- Schmutzhard J, Riedel H M, Wirgart B, Grillner L. Detection of herpes simplex virus type 1 , herpes simplex virus type 2 and varicella-zoster virus in skin lesions. Comparison of real-time PCR, nested PCR and virus isolation. J Clin Virol 2004; 29: 120-6.

7.- Burrows J, Nitsche A, Bayly B, Walker E, Higgins G, Kok T. Detection and subtyping of herpes simplex virus in clinical samples by 
LightCycler PCR, enzyme immunoassay and cell culture. BMC Microbiology.2002; 2: 12. www.biomedcentral.com

8.- Filén F, Strand A, Allard A, Blomberg J, Herrmann B. Duplex real-time polymerase chain reaction assay for detection and quantification of herpes simplex virus type 1 and herpes simplex virus type 2 in genital and cutaneous lesions. Sex Transm Dis 2004; 31 (6): 331-6.

9.- Page J, Taylor J, Tideman RL, Seifert C, Marks C, Cunningham A, et al. Is HSV serology useful for the management of first episode genital herpes? Sex Transm Infect 2003; 79: 276-9.

10.- Munday P E, Mullan H M. Clinical uses of herpes simplex virus type-specific serology. Int J STD \& AIDS 2001; 12: 784-8.

11.- Morrow R, Friedrich D. Performance of a novel test for IgM and $\mathrm{IgG}$ antibodies in subjects with culture-documented genital herpes simplex virus-1 or -2 infection. Clin Microbiol Infect 2006; 12: 463-9.

12.- Greer L, Weendel G. Rapid diagnostic methods in sexually transmitted infections. Infect Dis Clin North Am 2008; 22: 601-7.

13.- Muñoz LM, Peña $M$, Vinagre $C$, Fluxá $P$, Martínez M J. Seroprevalencia de herpes simplex-2 en una población de embarazadas, por dos test serológicos disponibles en Chile. XVII Congreso Chileno de Infectología. Viña de Mar, 9 al 12 de agosto de 2000. Libro de resúmenes P-76.

14.- Martínez M J, Navarrete N, Santander E, Garmendia M L, Gübelin W. Seroprevalencia de la infección por virus herpes simplex tipo 2 en pacientes atendidos en centros de referencia de ETS de Santiago. Rev Méd Chile 2005; 133 : 302-6.

15.- Luzoro A, Santander E, Gübelin W, Afani A, Martínez M J. Incidencia de Infección por virus herpes simplex tipo 2 en pacientes $\mathrm{VIH}+$ del área Norte de Santiago. IX Congreso Chileno de Dermatología y Venereología. Viña del Mar, 3 al 5 abril 2008. Libro de resúmenes. Resumen 70 , pg 68 .

16.- de Villiers E, Fauquet C, Broker T, Bernard H, zur Hausen H. Classification of papillomaviruses. Virology 2004; 324: 17-27.

17.- Muñoz N, Castellsagué X, Berrington A, Gissmann L. Chapter 1: HPV in the etiology of human cancer. Vaccine 2006; 24: S3 S3/1$\mathrm{S} 3 / 10$

18.- Palefsky J M. Cutaneous and genital HPVassociated lesions in HIV infected patients. Clin Dermatol 1997; 15: 439-47.

19.- Lee S, Vigliotti V, Vigliotti J, Pappu S. Routine human papillomavirus genotyping by DNA sequencing in community hospital laboratories. Infect Agents Cancer 2007; 2: 11

20.- Brink A, Snijders P, Meijer C. HPV detection methods. Dis Markers 2007; 23: 273-81.

21.- Brink A, Lloveras B, Nindl I, Heideman D, Kramer D, Pol R, et al. Development of a general- primer-PCR-reverse-line-blotting system for detection of beta and gamma cutaneous human papillomaviruses. J Clin Microbiol. 2005; 43(11): 5581-7.

22.- Stanley M. Immune responses to human papillomavirus. Vaccine 2006; 24 (Suppl 1): S16-22. 